\title{
EL LLANTO DE ESPAÑA: UN EPISODIO DE LAS RELACIONES LITERARIAS ENTRE ESPAÑA Y ARGENTINA
}

Licenciado en Filosofía y Letras por la Universidad de Alicante. Ha centrado su actividad investigadora en la poesía argentina de vanguardia. Ha publicado diversos artículos críticos y colaborado en la edición de Nuevos Textos para la Literatura Hispanoamericana Colonial (2000). Ha publicado recientemente Buenos Aires entre dos calles: breve panorama de la vanguardia poética argentina.

\author{
PEDRo MENDIola OÑate
}

\begin{abstract}
¿Que muerte enamorada de su muerte! Qué fusilado corazón tan vivo! ¿Qué luna de ceniza tan ardiente en donde se desploma Federico!
\end{abstract}

Raúl González Tuñón

«Como el niño que enseña lleno de asombro a su madre vestida de color vivo para la fiesta, así quiero mostraros hoy a mi ciudad natal. A la ciudad de Granada». Con estas palabras comenzaba Federico García Lorca su conocida conferencia «Cómo canta una ciudad de noviembre a noviembre» ${ }^{1}$, el 26 de octubre de 1933 en los salones de la Sociedad de Amigos del Arte de la no menos cantada ciudad de Buenos Aires. La noche anterior, su obra Bodas de sangre triunfaba en el Teatro Avenida de la mano de Lola Membrives, aunque a esas alturas, la ciudad entera se había rendido ya ante el duende deslumbrante del poeta granadino: «más que el aplauso agradece el poeta la sonrisa de viejo amigo que me ofrece el aire luminoso de la Avenida de $\mathrm{Ma}$ yo»².

A sus espaldas, Federico había dejado su tierra sumida en un complejo momento politico. En noviembre de 1933, después de dos años de complicado gobierno republicano, $y$ tras unos últimos meses de recesión económica e insurrecciones obreras, Niceto Alcalá Zamora decidía convocar unas elecciones generales que iban a decantar la balanza política española decididamente hacia la derecha. La preocupación del poeta por estas circunstan-

cias quedaría inmediatamente reflejada en su correspondencia y en sus declaraciones a la prensa bonaerense ${ }^{3}$.

La estancia de García Lorca en la capital argentina se vio prolongada durante largos meses de representaciones, tertulias, conferencias, banquetes y celebraciones de toda índole. Se resistía el poeta a despedirse de su Teatro Avenida, de las veladas en los sótanos del Castelar, de la amistad fraterna de Neruda, del aire lejanamente español de la Avenida de Mayo: "Por favor, mañana, en el barco, estaréis todos alegres. Haremos cuenta que me voy al Tigre, que nos volveremos a ver al otro día»4 . A pesar de estas invocaciones, el 27 de marzo de 1934, Lorca partía de Buenos Aires para no regresar jamás. Apenas dos años más tarde, el cuerpo de Federico caía fusilado sobre los campos de Granada, tan sólo un mes después del inicio de la Guerra Civil española. El poeta asesinado, nadie parece creerlo, algo impensable; la siniestra realidad de la guerra española empezaba a tomar posiciones en las conciencias de todo el

1

Federico García Lorca, Obras, VI, Prosa 1, Madrid, Akal, 1994 , p. 314.

\section{2}

Federico García Lorca, "Al público de Buenos Aires», ibidem, p. 401. Publicado originariamente en La Nación,
Buenos Aires, 26 de octubre de 1933.

3

En carta a su familia, fechada en Buenos Aires el 20 de octubre de 1933, escribe Federico: «De España leo noticias desagradables. Estas elecciones van a ser terribles. ¡Veremos qué pasa! Yo tengo verdadera ansiedad por todos esos movimientos políiticos». En Federico García Lorca, Obras, VI, Prosa 2, Madrid, Akal, 1994, p. 1139. $Y$ en una entrevista publicada en el diario Críica el día siguiente de su llegada al puerto de Buenos Aires, declaraba el poeta que «si bien hay en España una fuerte reacción de derecha, el pueblo español, que ama y gusta la libertad, está en la izquierda" ("Vengo de torero herido y a dar 4 conferencias...», Crítica, Buenos Aires, 14 de octubre de 1933). Debo este texto a la amabilidad de Antonio Román, Jefe de Departamento de Biblioteca, Centro de Documentación y Traducciones del Ministerio de Justicia y Derechos Humanos de la República Argentina.

4

Chas de Cruz, "Han pasado dos poetas. El español Federico Garcia Lorca y el chileno Pablo $\mathrm{Ne}$ ruda, viajeros del mundo, regaron con su lirismo las calles de la ciudad», El Suplemento. Primer Magazine Argentino, Buenos Aires, año XV, núm. 562, 25 de abril de 1934. Tomo la cita de Ian Gibson, Federico García Lorca, Barcelona, Grijalbo, 1987, t. II.

El llanto de España: un episodio de las relaciones literarias entre España y Argentina

PEDRO MENDIOLA ONATE 


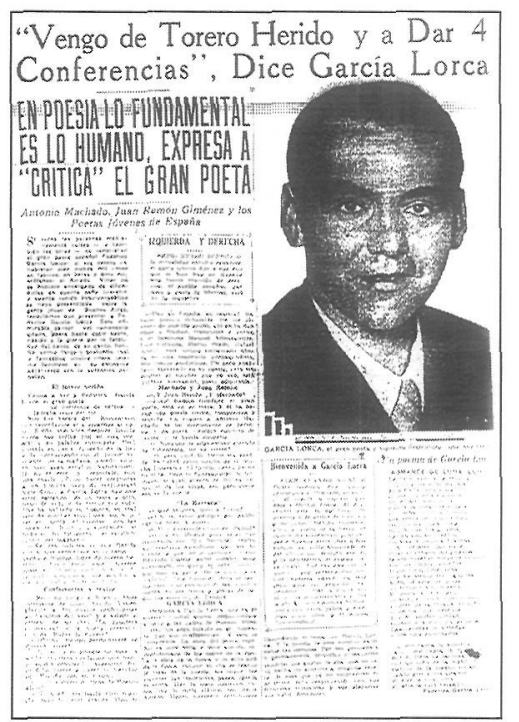

Lorca en la prensa bonaerense.

5

A propósito de la pugna entre «hispanofobia» e «hispanofilia» en el seno de la cultura argentina pueden consultarse los libros de Arturo Berenguer Carisomo, España en la Argentina (ensayo sobre una contribución a la cultura nacional), Buenos Aires, Club Español, 1953; y Rafael Alberto Arrieta, La literatura argentina y sus vínculos con Espa$\tilde{n} a$, Buenos Aires, Ed. Uruguay, 1957.

6

Cf. Alonso Zamora Vicente, Historia de la Real Academia Española, Madrid, Espasa Calpe, 1999, pp. 249-250.

7

Cf. Emilia de Zuleta, Relaciones literarias entre España y la Argentina, Madrid, Ediciones Cultura Hispánica, 1983, p. 23.

8

Cf. Daniel Rivadulla Barrientos, La "amistad irreconciliable». España y Argentina, 1900-1914, Madrid, MAPFRE, 1992.

9

«Mensaje de Miguel de Unamuno a la juventud argentina», Nosotros, Buenos Aires, año $\mathrm{XV}$, julio de 1921, núm. 146, pp. 285-287.

El llanto de España: un episodio de las relaciones literarias entre España y Argentina

PEDRO MENDIOLA ONATE mundo. Sin embargo, aquella brecha abierta en el seno de la joven poesía española ayudaría a cerrar algunas viejas cicatrices en las relaciones intelectuales entre España y Argentina. Símbolo atroz de un conflicto civil que reclamaba implicaciones ajenas y que, como trataremos de ver en adelante, iba a representar un importante refuerzo de las implicaciones culturales, políticas y sociales entre ambos países.

Pero hasta llegar a ese momento, el cauce de las relaciones entre España y Argentina fue tan largo y proceloso como el que condujo a los navegantes españoles hasta las prometedoras aguas del Río de la Plata. Es significativo, por ejemplo, que hubieran de pasar casi diez lustros para que ambos países firmaran un Tratado de Reconocimiento, Paz y Amistad (9 de julio de 1859), tras la Revolución que había iniciado la Independencia argentina en mayo de 1810. Precisamente, el hecho de que Buenos Aires fuera el primer enclave de ultramar en poner en duda el orden colonial peninsular, debió influir a buen seguro para que los intelectuales argentinos decidieran alejarse prontamente de las sendas culturales que discurrían por la España convulsa del XIX. El paternalismo intelectual era una situación tanto o más intolerable que el tutelaje político ${ }^{5}$, y ese sentimiento se mantuvo en Argentina, de forma más o menos intensa, hasta bien entrado el siglo XX, llegando a posiciones extremas, como la renuncia de Juan María Gutiérrez al puesto de correspondiente de la Real Academia Española en $1875^{\circ}$. Las primeras décadas del siglo XX trajeron consigo un cierto atemperamiento en las relaciones culturales de ambas naciones: con el desarrollo del regeneracionismo español, por un lado, que favoreció un cierto acercamiento hacia lo americano; y con la llegada de Darío y el modernismo a Buenos Aires, que originó, por otro lado, un «reencuentro con lo hispánico» ${ }^{7}$, cuyos mejores frutos habrían de buscarse tal vez en los ensayos de Ricardo Rojas, El alma española: ensayos sobre la moderna literatura castellana (1907), y Manuel Gálvez, El solar de la raza (1907); y en buena parte de la producción poética de $\mathrm{Bal}$ domero Fernández Moreno. Dispar y contradictorio inventario de gestos que forman par- te de la compleja historia de las relaciones políticas, económicas y culturales entre España y Argentina, siempre en el límite difuso entre la confraternidad y la «amistad irreconciliable»8.

\section{HACIA EL DOLOR DE ESPAÑA: EL PROCESO A UNAMUNO}

Es obvio que no pasaba desapercibida en los circuitos culturales argentinos la situación política e intelectual que se vivía en España. No podía hacerlo en una sociedad compuesta en gran número por añorantes inmigrantes españoles y descendientes más o menos directos de estos. En este sentido, las sucesivas quijotadas de Miguel de Unamuno contra la monarquía y la dictadura españolas tuvieron en Buenos Aires una intensa repercusión cultural.

Desde mediados de 1902, momento en el que Alfonso de Borbón y Habsburgo había tomado posesión del trono de España, el país arrastraba una permanente situación de inestabilidad política, poblada de huelgas, manifestaciones, atentados, cargas policiales y continuos cambios de gobierno. Se vivía un proceso de dègradación política que había de alcanzar su punto álgido el 24 de marzo de 1919 con la suspensión de las garantías constitucionales. A partir de esa fecha se acrecientan las denuncias de Unamuno frente a la agonía moral de la clase política española, al extremo de ser destituido de sus cargos académicos y condenado - para ser indultado más tarde, a modo de escarmiento- por «delito de lesa majestad».

La condena levantó en Argentina una efervescente protesta estudiantil, que el «ex Rector de la Universidad de Salamanca» agradeció en una carta publicada en julio de 1921 en la revista porteña Nosotros:

...permitan que un español que ha tomado sobre sílos dolores y vergüienzas de miles de españoles movidos de terror o de pena, un español que ha ensanchado a España al hacer que su voz se oiga donde nuestro común verbo resuena, les pida que acudan como puedan en ayuda de este pobre pueblo explotado, oprimido y envilecido por el hipócrita despotismo habsburguiano?.

A Unamuno le había tocado vivir en la España envejecida del 98, la España declinante del desastre colonial, sin embargo, su actitud 
frente a lo americano estuvo marcada siempre por los principios de concordia, de respeto y de igualdad ${ }^{10}$. Buen conocedor de la cultura y la historia argentina, don Miguel había leído con profusión a los poetas gauchescos, admiraba la figura de Sarmiento y mantenía regular correspondencia con numerosos intelectuales argentinos. El lector de Buenos Aires tenía también una cierta noción del ideario crítico del escritor vasco a través de las colaboraciones que Unamuno publicó regularmente en el diario La Nación, entre 1906 y $1924^{11}$.

La situación política en España había empeorado en septiembre de 1923 con la implantación de una dictadura militar comandada por el general Miguel Primo de Rivera. En noviembre de ese mismo año, Unamuno escribía una descarnada carta a un profesor español residente en Buenos Aires, que la revista Nosotros transcribió de manera fragmentaria en su número de diciembre:

Me ahogo, me ahogo, me ahogo en este albañal y me duele España en el cogollo del corazón.

[...]

¡Quién me había de decir que al acercarme a los sesenta, sentiría el peso de aquella cancerosa tradición, de aquel tradicional cáncer que hacía estallar bombas sobre mi cabeza cuando tenía diez años. ¡Pobre España! ¡Pobre España! ¡Pobre España! Dan ganas de morirse $^{12}$.

El nacimiento de Nosotros en 1907, recuerda Emilia de Zuleta, había contribuido decisivamente a la «integración hispánica» ${ }^{13}$ en el seno del ambiente cultural bonaerense. Sin embargo, la publicación de la mencionada carta en la revista porteña, lejos de ayudar al literato español, parece ser uno de los pretextos de los que se sirvió el Directorio Militar para decretar su destierro a la isla de Fuerteventura, el 20 de febrero de 1924. La protesta argentina fue unánime e inmediata. En primer lugar, a través de un manifiesto aparecido ese mismo mes en Nosotros, bajo las firmas, entre otros, de Ricardo Rojas, Roberto J. Payró, José Ingenieros, Arturo Capdevila, Arturo Cancela, Alfonsina Storni, Julio Noé, Rafael Alberto Arrieta, Roberto F. Giusti, Héctor Pedro Blomberg o Enrique Méndez Calzada ${ }^{14}$. Curiosamente, entre los firmantes, representantes en su mayoría de la llamada Generación del Centenario, no apa-

rece ninguno de los jóvenes escritores que por esas fechas trataban de organizar en la capital rioplatense una genuina literatura de vanguardia, y que en la década siguiente dejarían testimonio de la repercusión en Argentina de la Guerra Civil española.

La contundente res-

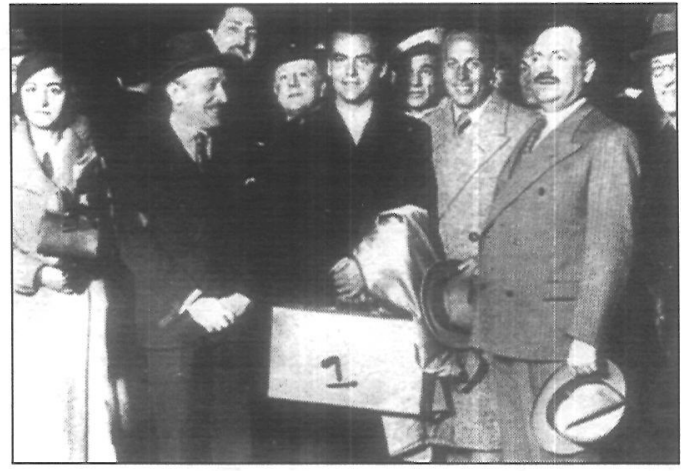

Llegada de Lorca a Buenos Aires. puesta de los jóvenes intelectuales bonaerenses iba a aparecer en la recién fundada revista Martín Fierro, principal órgano difusor de la estética de avanzada en Buenos Aires. La revista abría su segundo número con un incendiario artículo dedicado a «El caso Unamuno». El texto, como era de esperar, lamenta la situación del escritor vasco y el proceso político que sufre España, no obstante, censura severamente el condescendiente ademán hispanófilo que se deja traslucir de la protesta oficial argentina:

Antes, y muy particularmente ahora, ser hispanófilo es ser antiargentino. Aunque hablando el español, aunque siendo nuestro pueblo de origen español, nada tiene que ver el actual espíritu argentino, su pueblo, eminentemente cosmopolita -formado por hombres de todas las razas, y por millones de sus descendientes, que son educados en una ideología y viven con un pensamiento muy diverso, contrario, al de España,- con el espíritu y las costumbres de ese país, cosas cuyo resabio constituye todavía el peor lastre del pueblo argentino-. Y sostenemos, clamorosamente, que necesitamos, ahora, ante la invasión del hispanismo, ya se trate de elementos étnicos, de la inmigración española, como de la penetración espiritual, por la literatura y el arte españoles, de la más mediocre, cuando no subalterna calidad $-\mathrm{y}$ no aludimos sólo a la ola de inmundicia de sus innumerables cultores de la pornografía, - sostenemos clamorosamente, decimos, la necesidad de un nuevo 25 de Mayo, en el orden moral e intelectual. [...]

10

En carta al ensayista argentino Ricardo Rojas escribe don Miguel: "Tenemos que acabar de perder los españoles todo lo que se encierra en eso de madre patria, y comprender que para salvar la cultura his- pánica nos es preciso entrar a trabajarla de par con los pueblos americanos, y recibiendo de ellos, no sólo dándoles [...] Todo eso se corregirá el día en que nosotros los españoles abandonemos la necia pretensión de seguir siendo, ni en lenguaje ni en nada, la metrópoli, la madre patria, la que dirige y da la ley, y cesemos de ver en esas repúblicas hijuelas nuestras». Cito por Julio César Chaves, Unamuno y América, Madrid, Ediciones Cultura Hispánica, 1970, p. 19

11

CF. Miguel de Unamuno, Artículos en "La Nación» de Buenos Aires (1919-1924), ed. de Lovis Urrutia, Salamanca, Ediciones Universidad de Salamanca, 1994; y Miguel de Unamuno, De patriotismo espiritual: artículos en «La Nación» de Buenos Aires: 1901-1914, ed. de Victor Ouimette, Salamanca, Ediciones Universidad de Salamanca, 1997.

12

«Un grito en el corazón: hermosas palabras de un hombre libre», Nosotros, Buenos Aires, núm. 175, dic. de 1923, p. 521.

13

Cf. Emilia de Zuleta, op. cit., pp. 13-59.

14

Precisamente, algunos de estos nombres aparecían, junto a los de Joaquín V. González, Enrique Larreta, Leopoldo Lugones, Alberto del Solar, Mariano de Vedia, Álvaro Melián Lafinur y otros, en una publicación de evidente orientación hispanófila aparecida en 1921 con el inequívoco título de: Homenaje que rinde a España la Mayor de sus hijas, Buenos Aires, José Ricardo Rosenvald, editor, 1921.

El llanto de España: un episodio de las relaciones literarias entre España y Argentina

PEDRO MENDIOLA OÑATE 


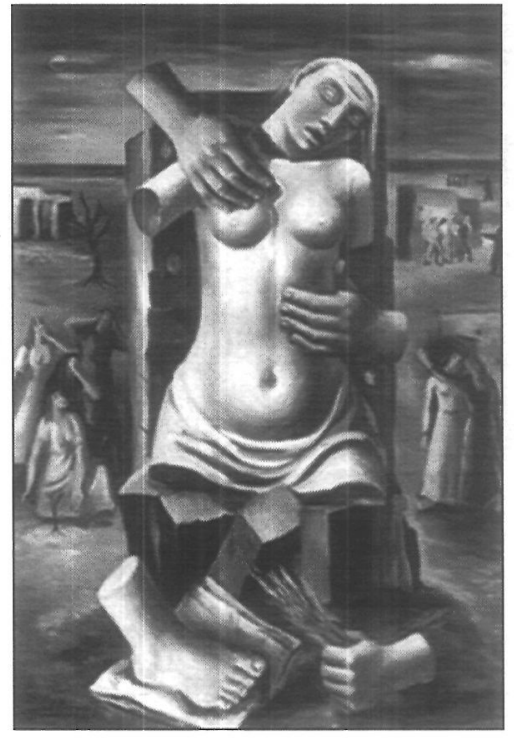

Raquel Forner, «La victoria», 1939

15

Severo Franco, «El caso Unamuno», Martín Fierro, Buenos Aires, $2^{9}$ época, año $1^{\circ}$, núm. 2, marzo 20 de 1924, p. 3

16

A propósito de esta polémica puede verse el estudio de Carmen Alemany Bay, La polémica del meridiano intelectual de Hispanoamérica (1927). Estudio y textos, Alicante, Universidad de Alicante, 1998.

\section{7}

Jorge Luis Borges, "Sobre el meridiano de una gaceta», Martín Fierro, Buenos Aires, $2^{a}$ época año $\mathrm{IV}$, núm. 42, junio 10 -julio 10 de 1927.

\section{8}

Cf. Fernando Schwartz, La internacionalización de la guerra civil española: julio de 1936-marzo de 1937, Barcelona, Ariel, 1972; Enrique Moradiellos, El reñidero de Europa. Las dimensiones internacionales de la guerra civil española, Barcelona, $\mathrm{Pe}$ nínsula, 2001.

19

Juan Larrea, César Vallejo y el surrealismo, Madrid, Visor, 1976, p. 211.

El llanto de España: un episodio de las relaciones literarias entre España y Argentina

PEDRO MENDIOLA OÑATE

Aunque Unamuno se halle lejos de nuestra sensibilidad, declaramos que se le conoce bastante. Y está bien. Pero no se trataba de eso, al ocuparse de Unamuno. El caso de este es el síntoma sólo del estado de putrefacción de su raza, de su país ${ }^{15}$.

En realidad, debemos entender la respuesta de la iconoclasta juventud «martinfierrista», por un lado, como un gesto de autoafirmación dentro del campo intelectual bonaerense $y$, al mismo tiempo, de distanciamiento respecto a las generaciones literarias anteriores; $y$ por otro, como una legitimación de la vanguardia autóctona, en oposición a cualquier vestigio de injerencia o primacía cultural de procedencia española.

El 10 de febrero de 1926 llegaba a Buenos Aires el hidroavión español «Plus U1tra», inaugurando la única vía de comunicación que, en teoría, separaba la Argentina de la Península Ibérica. Sin embargo, el distanciamiento intelectual entre españoles y argentinos se mantendría de manera intermitente a lo largo de toda la década del veinte, alcanzando su momento crítico en 1927 con motivo de la polémica mantenida entre Martín Fierro y La Gaceta literaria, acerca de un pretendido «Meridiano intelectual de Hispanoamérica» ${ }^{16}$ con sede en Madrid, y que puede resumirse en la frase de Borges: «Madrid no nos entiende» ${ }^{17}$.

\section{6: ESPAÑA ENTRE EL CLAVEL Y LA ESPADA}

Forma ya parte de la mitología urbana de Buenos Aires la disputa abierta entre los cafés españoles de la Avenida de Mayo con motivo del inicio de la Guerra Civil española. Como una metáfora amarga de la tragedia que dividía a España, reprodujeron de una a otra vereda el fuego cruzado de injurias, acusaciones y reproches que trazaban las balas en los frentes peninsulares a más de diez mil kilómetros

20

Cf. Marc Hanrez (ed.), Los es- Puede consultarse una edición critores y la Guerra de España, facsímil digital de ambos poBarcelona, José Batlló, 1977. emarios en la Biblioteca Virtual Miguel de Cervantes (www.cervantesvirtual.com). de distancia. La capital argentina se disponía en aquel momento a celebrar el cuarto centenario de su fundación, pero no era aquél año propicio para conmemoraciones ni festejos.

La dimensión internacional de la Guerra Civil española ya ha sido puesta de manifiesto por numerosos estudiosos e historiadores ${ }^{18}$. Europa miraba con preocupación las consecuencias terribles de un proceso que podía interpretarse como un desenlace augural de los problemas que arrastraba el viejo continente tras la Guerra del 14. En este sentido, la contienda española encarna, en palabras de Juan Larrea, «el enfrentamiento que, por representar en términos prototípicos la situación general del planeta entre las márgenes del pasado y del porvenir, sublevó hasta la exasperación las pasiones más desinteresadas del mundo entero, al grado que de todos los rumbos acudieron voluntarios a sacrificar sus existencias en aquel fuego donde sentían fraguarse el destino del ser humano en su plenitud» ${ }^{19}$. En este proceso, es innegable la importancia de los artistas - en especial los literatos - de Europa y otras latitudes, que, asumiendo el conflicto español como una herida abierta en carne propia, entregaron sus voces al lamento desgarrado de un pueblo, y aun no resignándose a blandir su pluma contra el sistema opresor, pisaron la misma tierra y empuñaron las mismas armas que el ejército del pueblo, engrosando las filas de las célebres Brigadas Internacionales.

En Europa, los corifeos de la vanguardia histórica, que ya evidenciaban en la década del treinta un paulatino y sosegado repliegue hacia posiciones de retaguardia, no dudaron en alzar sus voces contra la sinrazón e iniquidad de la guerra: tales fueron los casos de Louis Aragon, Paul Elouard, André Breton o Tristan Tzara. Otros escritores principales dejaron también testimonio de su pesar por los dolorosos acontecimientos que estaban desmembrando la sociedad española: Ernest Hemingway, George Orwell, John Dos Passos, André Malraux o Jean Paul Sartre ${ }^{20}$, por citar los nombres de mayor relieve. En América Latina, las repercusiones fueron igualmente inmediatas. Nicolás Guillén compuso en 1937 España. Poema en cuatro angustias y una esperanza; y ese mismo año, Pablo Neruda publicó milagrosamente su España en el corazón, bimno a las glorias del pueblo en la guerra (1936-1937)21, en una imprenta improvisada por Manuel Altolaguirre en pleno frente, con 
la ayuda de los propios soldados; e igual fortuna corría el último aliento poético de César Vallejo, España, aparta de mí este cáliz, editado por los soldados de la República en el año de 1939.

La repercusión de la guerra de España entre los intelectuales argentinos, a pesar de los titubeos y reticencias que hemos venido señalando, fue igualmente rotunda, aunque no exenta de algunas posiciones dudosas o inciertas. En opinión del historiador argentino José Luis Romero:

El estallido de la guerra civil española en 1936 provocó en el país una polarización de opiniones, y el apoyo a la causa republicana constituyó una intencionada expansión para quienes deseaban expresar su repudio al gobierno ${ }^{22}$.

El 17 de agosto de 1936, el gobierno de Uruguay hacía un llamamiento a todos los gobiernos de América con el fin de alcanzar un acuerdo de mediación internacional a cargo de las naciones americanas: «Ante la guerra civil que asola a España, las naciones del continente americano, que ha sido descubierto y colonizado por el espíritu español, no pueden permanecer impasibles»23. La iniciativa uruguaya, como recoge Francisco Virgilio Sevillano, no llegó a buen término, y el gobierno argentino se acogió al principio de No-intervención, aduciendo que «la mediación sería inoperante, en tanto no se reconociese la cualidad de beligerantes a los insurrectos» ${ }^{24}$.

El gobierno de Agustín P. Justo, heredero del golpe militar de 1930, parecía tender sobre sus intenciones el manto incierto de la neutralidad. Sin embargo, algunos testimonios de la época dictaminan claramente la verdadera inclinación de la postura oficial argentina. Anotamos, a modo de ejemplo, varias comunicaciones de Alfonso Reyes, en aquel tiempo embajador de México en Buenos Aires, en las que el escritor y diplomático apuntaba «la situación de hostilidad reinante entre las autoridades argentinas contra los intereses de la República española y de los españoles leales al gobierno legítimo de aquel país» ${ }^{25}$. Y en otro comunicado, atestigua: «Se ha repetido el hecho de que la autoridad prohíba manifestaciones y homenajes de simpatía pública al Frente Popular español, mientras por otra parte autoriza actos semejantes de simpatía a la Junta de Burgos»26. A pesar de todo, la sociedad

argentina se movilizó rápidamente en favor de las víctimas de la guerra y en apoyo del Frente Popular español. Se organizaron comités de ayuda, campañas de recogida de ropa y alimentos, multitudinarias manifestaciones públicas, e incluso algunos voluntarios acudieron a España

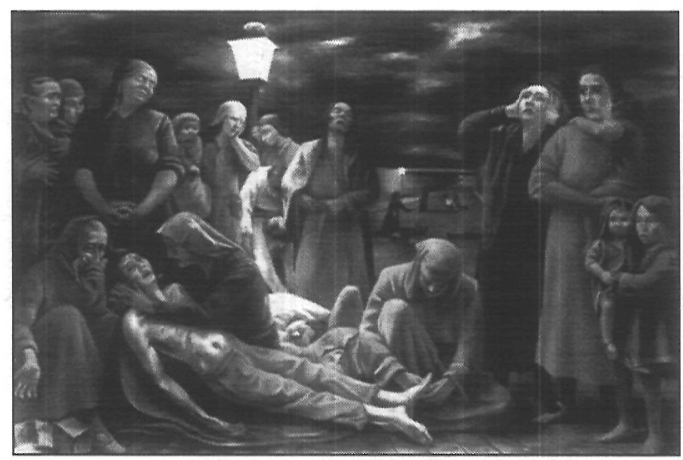

Antonio Berni, «Medianoche en el mundo», 1936-37.

para alistarse en los dis-

tintos batallones de las Brigadas Internaciona$\operatorname{les}^{27}$.

La disposición de los intelectuales argentinos estuvo también mayoritariamente del lado republicano. El 11 de septiembre de 1936, aparecía en El Socialista de Madrid un manifiesto firmado por las principales voces ${ }^{28} \mathrm{de}$ la literatura argentina en el que daban un respaldo casi fraternal a la causa española:

La guerra civil que ensangrienta hoy a España y la divide en dos grandes bandos, inquieta y angustia por igual a millones de hombres que viven fuera de sus fronteras. Guerra social, por consiguiente, en la que ha de definirse algo más que una victoria para quienes hoy disputan el gobierno de España, nos mueve a romper nuestro silencio.

Desde el advenimiento de la República, España está más cerca de nosotros. Sus conflictos repercuten en Argentina con mayor intensidad que los conflictos de cualquier otro país del mundo, y los hogares argentinos siguen hoy la lucha como si estuvieran combatiendo nuestros hermanos ${ }^{29}$.

El texto es sumamente revelador, no sólo por el rechazo a la guerra y el apoyo sin fisuras al bando republicano, sino también por-

22

José Luis Romero, Breve historia de la Argentina, Buenos Aires, Fondo de Cultura Económica, 2000, p. 148.

23

"Copia del telegrama-cable que el Gobierno del Uruguay dirigió a todos los Gobiernos de América, con fecha del 17 de agosto de 1936, sobre mediación en España», publicada en Revue internacionales francaise du droit des gens, París,
15 de septiembre de 1936. Reproducido en Francisco Virgilio Sevillano Carbajal, La diplomacia mundial ante la guerra española, Madrid, Editora Nacional, 1969, p. 224.

24

Cf. Francisco Virgilio Sevillano Carvajal, ibidem.

25

Alfonso Reyes, «Continúan las hostilidades de las autoridades argentinas contra los intereses de la España republicana», Buenos Aires, 6 de enero de 1937. Recogido por Alberto Enríquez Perea, Alfonso Reyes y el llanto de España en Buenos Aires, México, El Colegio de México / Secretaría de Relaciones exteriores, 1998, p. 167.

26

Alfonso Reyes, «Las autoridades argentinas prohíben manifestaciones y homenajes al Frente Popular español. Sí autorizan aquellas que simpaticen con la Junta de Burgos», Buenos Aires, 30 de octubre de 1936. Recogido por Alberto Enríquez Perea, ibidem, p. 151.

27

Cf. el informe redactado por el Grupo de Voluntarios Argentinos del Ejército Popular Español para la publicación colectiva La solidaridad de los pueblos con la República Española 1936-1939, Editorial Progreso, Moscú, 1974, pp. 54-62.

28

Entre otros, aparecen las firmas de Enrique Amorim, Leónidas Barletta, Jorge Luis Borges, Mario Bravo, Roberto F. Giusti, Alberto Gerchunoff, Eduardo Mallea, Ricardo Molinari, Conrado Nalé Roxlo, Victoria Ocampo, Aníbal Ponce, Pablo Rojas Paz, Alfonsina Storni o César Tiempo.

29

"Desde la implantación de la República, España está más cerca de nosotros". Recogido por Alberto Enríquez Perea, ibidem, p. 289.

El llanto de España: un episodio de las relaciones literarias entre España y Argentina

PEDRO MENDIOLA OÑATE 


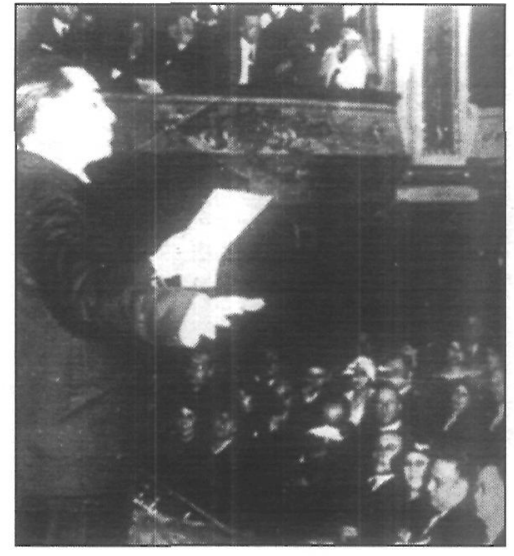

Lorca en el Teatro Avenida de Buenos Aires. que retoma una vez más el asunto siempre complejo de las relaciones entre ambas naciones, relaciones que un gobierno militar en España podía nuevamente desorientar.

Al margen de estas consideraciones, el asesinato de García Lorca representa tal vez el desencadenante definitivo de la toma de conciencia por parte de la intelectualidad argentina. Cundía el desaliento entre los que le habían conocido, a medida que se iba confirmando la veracidad de la noticia. Lorca había muerto fusilado el 18 de agosto de 1936, justo 30

Amado Alonso, «Es terrible pensar que haya muerto el gran poeta flamenco", Crííica, Buenos Aires, 17 de septiembre de 1936.

31

«Telegrama a la Junta de Burgos», Críitica, Buenos Aires, 17 de septiembre de 1936. Debo estas referencias a la amistad inestimable de Verónica Zumárraga.

\section{2}

Cf. César de Vicente Hernando (ed.), Poesía de la Guerra Civil española, Madrid, Akal, 1994, p. 15.

33

Adolfo Prieto, «Conflictos generacionales», en César Fernández Moreno (coord.), America Latina en su literatura, México, Siglo veintiuno editores, 1986, p. 411

34

Oliverio Girondo, Obra, Buenos Aires, Losada, 1994, pp. 250251.

El llanto de España: un episodio de las relaciones literarias entre España y Argentina

PEDRO MENDIOLA OÑATE un mes después del estallido de la guerra, el 18 de julio, irónicamente día de San Federico. Casi un mes tardó en confirmarse la noticia de su muerte en Buenos Aires. «No puedo convencerme de que hayan fusilado a García Lorca: No quiero, no puedo creer ${ }^{30}$, se aferraba todavía su compatriota Amado Alonso cuando ya las evidencias del triste desenlace comenzaban a deshacer cualquier posibilidad de incertidumbre. Inmediatamente, la prensa bonaerense comenzó a hacerse eco de la noticia, e incluso, el 17 de septiembre, el diario Crítica publicó un telegrama de indignación enviado al general Cabanellas de la Junta militar de Burgos:

En nombre de la civilización y la cultura ultrajadas con ese crimen injustificable, nosotros, escritores argentinos identificados con la causa de la civilización, que encarnan en este momento las armas de la República, protestamos ante Vd. con nuestra máxima vehemencia y le decimos que la noble sangre de Federico García Lorca, que sólo corrió impulsada por el amor a la belleza y a la justicia, ha puesto una nueva mancha, imborrable esta vez, sobre las espadas culpables de su muerte ${ }^{31}$.

\section{POEMAS DE LA ROSA BLINDADA}

El corpus poético generado por la Guerra Civil española, tanto en la península como fuera de ella, no debe ser considerado como un simple compendio documental. Es cierto que en España hizo brotar un notable romancero de circunstancia, de poemas sueltos que circularon por los frentes y los pueblos, publicados precariamente en revistas o panfletos de escasa tirada, sin embargo, como advierte César de Vicente, no debemos olvidar «que en toda escritura subyace una «poética»»32.

Parece evidente que algo había empezado a cambiar en el seno de la poesía argentina a lo largo de toda la década del treinta. La profunda depresión económica provocada por el famoso crack del 29 y el golpe de Estado que derrocara el gobierno de Hipólito Yrigoyen en septiembre de 1930, habían iniciado en las letras argentinas un proceso de reflexión social, que la catástrofe de la guerra civil española ayudó, directa o indirectamente, a consolidar. En opinión de Adolfo Prieto, «el fermento ideológico, el «sentido deportivo de la vida» de los años iniciales de la década del veinte, derivó luego en el stalinismo, los regímenes de Hitler y Mussolini, la gran crisis económica del 29, la tragedia civil española, los confusos acontecimientos que llevaron a la segunda guerra mundial»33. Un periplo que representa en Argentina el tránsito entre los representantes de la vanguardia - la llamada generación del 22- y la generación poética argentina de los años cuarenta.

Que la contienda española se había infiltrado en el interior de la imaginación creativa argentina lo demuestra tal vez la publicación en 1937 del relato Interlunio de Oliverio Girondo. El libro, encuadernado con rigurosas tapas negras e ilustrado por las estremecedoras aguafuertes de Lino Spilimbergo, representa el principio de un decisivo cambio formal en la obra del poeta, que conduce su discurso desde el mundo sensorial hasta el interior de un universo puramente emocional. Oliverio no alude directamente a la guerra civil, pero ésta subyace como una presencia terrible en el fondo del relato:

Europa es como yo - solía decir- algo podrido y exquisito; un Camembert con ataxia locomotriz. Es inútil untarla con malos olores. La tierra ya no da más. Es demasiado vieja. Está llena de muertos. Y lo que es peor aún, de muertos importantes ${ }^{34}$.

También en 1937, Roberto Gómez publica en Buenos Aires un curioso libro titulado Charlas de café sobre la Guerra Civil española: julio 1936-1937 (Buenos Aires, Acento, 1937) y al año siguiente Elías Castelnuovo retoma el asunto en Resurrección. Impresiones de una conciencia libre sobre la epopeya beroica del pueblo español (Buenos Aires, Ed. Claridad, 1938). Son tiempos de ceniza, de 
"sonrisa pisoteada», de «inocencia degollada», dirá también Eduardo González Lanuza en La degollación de los inocentes (1938). Pero fue sin duda el poeta Raúl González Tuñón quien trazó vínculos más estrechos con la lucha que se disputaba en las ciudades y los pueblos de España.

En la década del veinte, la poesía argentina aparece seccionada en dos tendencias, una artística y otra social, que dividieron el escenario de la ciudad literaria: la eterna disputa entre la revolución del Arte y la revolución del Hombre. En este sentido, Beatriz Sarlo entiende que «España enfrenta batallas finales donde todo puede quedar decidido para siempre; la guerra no tiene retorno y arranca a los intelectuales de sus rencillas parroquiales al proyectarlos sobre un fondo de decisiones planetarias» ${ }^{35}$. La obra de González Tuñón podría tomarse como un catalizador, un hilo conductor que incorpora esas dos mitades del círculo poético bonaerense. Entre Borges, Girondo y Molinari, por un lado, y Riccio, Yunque y Olivari, por el otro, deberíamos situar tal vez los primeros libros de Raúl González Tuñón: El violín del diablo (1926) y Miércoles de ceniza (1928). En 1935, Tuñón, ya en las filas del partido comunista, viaja a España donde traba conocimiento del fracasado alzamiento de los mineros de Asturias, en octubre de 1934, y puede percibir los primeros indicios de una incipiente contienda civil. Tras ese viaje, publica Todos bailan (1935), en el que su escritura evidencia el giro definitivo hacia una poesía «militante»:

A los veinte años sólo creíamos en el Arte, sin la vida, sin la Revolución $n^{36}$.

Tal vez sus primeras composiciones en torno a la guerra de España aparecieron, junto a otras de Rafael Alberti o W. H. Auden en una publicación titulada Los poetas del mundo defienden al pueblo españo [37, que editaba Nancy Cunard con la ayuda de Pablo Neruda, en una pequeña imprenta cerca de París. En 1936 se publicaron en Buenos Aires diversos libros referentes a la guerra de España, subvencionados por la editorial de la Federación de Organismos de Ayuda a la República Española y otras instituciones progresistas, entre los cuales destacaba un libro de poemas: La rosa blindada de Raúl González Tuñón, cuyos poemas, gestados en su viaje a la España previa al inicio de la guerra, están dedicados al alzamiento de los mineros asturianos:

Cuando desfilan los guardias de asalto, cuando el obispo revista las tropas, cuando el verdugo tortura al minero, ella, agitando su túnica roja, quiere salir de la tumba del viento, quiere salir y llamaros hermanos y renovaros valor y esperanza y recordaros la fecha de Octubre cuando caían las frutas de acero y estaba toda manchada de España y estaba toda la novia de Octubre y estaba toda la rosa de Octubre y estaba toda la madre de España $a^{38}$.

La palabra poética se transforma entonces en consigna, en salvoconducto, en parte misma de la lucha; el poeta camina al lado del obrero; la tinta de la pluma fluye por los mismos cauces que recogen la sangre del soldado. Así lo refrenda el poeta en un texto de 1937 titulado Las puertas del fuego, cuando ya todo lo ensombrece la evidencia de la guerra:

Pero hoy, más que en la tinta, es en la sangre donde el escritor moja su pluma, si esa pluma no está al servicio de España, contra el fascismo y por la defensa de la cultura (sin que esto quiera decir que debe hacerse simple propaganda a base de panfleto y affiche), si esa pluma no se parece más que nunca a un arma, es preferible dejar que se oxide ${ }^{39}$.

Es entonces misión del poeta, no sólo denunciar la injusticia, condenar la ignominia, soportar la humillación, el dolor, el fracaso, la muerte; es su deber, tal vez con más fuerza que en cualquier otro momento, preservar la belleza, resguardarla del horror, de la violencia, de la incultura... blindar la rosa.

En 1937, González Tuñón viaja a París para participar en el II Congreso de Escritores Antifascistas, que le conduce en un larguísimo viaje en tren desde la capital francesa hasta Madrid, junto a Vallejo, Neruda o Huidobro. Allí, en aquel Madrid en ruinas, conoce González Tunón a un Miguel Hernández, a quien años después dedicaría su hermosa «Elegía en la muerte de Miguel Hernández» (Himno de pólvora, Santiago de Chile, 1943), y cuya figura evidenciaba entonces, como ninguna otra, la trágica unión del poeta y el soldado. La experiencia española vuelve a engendrar en 1939 un
35

Beatriz Sarlo, Una modernidad periférica: Buenos Aires 1920 y 1930, Buenos Aires, Nueva Visión, 1988, p. 137.

36

Raúl González Tuñón, «Cosas que ocurrieron el 17 de octubre», Todos bailan, en Juancito Caminador. Antología poética, Buenos Aires, Ameghino, 1998, p. 87.

37

Cf. Pablo Neruda, Confieso que he vivido, Madrid, Unidad Editorial, 1999, pp. 145-146.

38

Raúl González Tuñón, «La libertaria», La rosa blindada, en Juancito Caminador, op. cit., p. 113.

39

Raúl González Tuñón, Las puertas del fuego, Santiago de Chile, Ercilla, 1938, p. 210. Tomo la cita de Beatriz Sarlo, op. cit., pp. 137-138.

El llanto de España: un episodio de las relaciones literarias entre España y Argentina

PEDRO MENDIOLA OÑATE 
Raúl González Tuñón, «Los obuses (2)», La muerte en Madrid, Buenos Aires, Ediciones Feria, 1939 , p. 39.

41

Raúl González Tuñón, «Los escombros", ibidem, p. 43.

42

Palabras de Alberdi en 1839 citadas por Arturo Berenguer Carisomo, op. cit., p. 14.

\section{3}

Raúl González Tuñón, «Madrid», ibidem, p. 14.

44

Jorge Luis Borges, «España», $E$ I otro, el mismo, en Obra poética, Madrid, Alianza, 1972, pp. 249-250. nuevo libro de poemas, en esta ocasión, entorno a la fracasada defensa republicana de la capital: La muerte en Madrid. La expresión se torna más sombría, se extravía entre el silbido del obús y las columna de escombros, ante la vida trunca del héroe, del niño y del poeta, ante «el corazón caído» de la España herida. Pero esa imagen de España, resquebrajada y vencida, como «dos manos cortadas dentro de una guitarra ${ }^{40}$, había conseguido hermanar conciencias, derrotar fronteras ( «Hoy que un pueblo a la orilla del desastre orgulloso, / un pueblo en cuya voz habita la mañana, / se abre como la rosa sangrienta de la historia. / ¡El mundo empieza en la llanura castellana!) ${ }^{41}$. Había llegado tal vez la hora de América, la hora de aquella demanda que justo un siglo atrás hiciera Juan Bautista Alberdi: «tiranizados ellos como nosotros, fueron nuestros compañeros de opresión, como serán en adelante nuestros compañeros de libertad» ${ }^{42}$. Había llegado tal vez la hora de España y Argentina:

Lágrima abierta, corazón adentro, estoy al fin bajo tus arcos mártires. ¡Descúbreme otra vez! Yo soy América. [...]
De todas partes hacia ti venimos con fusiles o versos a tus muros. Flamante capital de todas partes, ¡novia del mundo!t3.

Tras el fin de la guerra, la diáspora intelectual provocada por la dictadura militar en España, siguió reforzando el entendimiento cultural entre los escritores, pensadores y artistas españoles y las jóvenes naciones americanas. A Buenos Aires llegaron entre otros Ramón Pérez de Ayala, Claudio Sánchez de Albornoz, Manuel de Falla y Rafael Alberti, quien seguirá ampliando las resonancias de la guerra con un libro de poemas publicado en la capital argentina por la editorial Losada en 1941: Entre el clavel y la espada.

Aquella «España silenciosa», la «España de la otra guitarra, la desgarrada $»^{44}$, que seguía cantando Borges treinta años después, había estremecido profundamente, y por qué no, había transformado, a toda una generación de artistas argentinos, e iba a condicionar también a buena parte de las generaciones argentinas posteriores, que en ese momento empezaban a tomar conciencia del mundo que les había tocado vivir y contar. 